\title{
FILTRAÇÃO EM MARGEM PARA INDUÇÃO DE RECARGA E MELHORIA DA QUALIDADE DE ÁGUA - ESTUDO DE CASO: RIO BEBERIBE
}

\author{
BANKFILTRATION FOR INDUCTION OF RECHARGE AND IMPROVEMENT OF \\ WATER QUALITY - CASE STUDY: BEBERIBE RIVER
}

\author{
Anderson Luiz Ribeiro de Paiva'; Jaime Joaquim da Silva Pereira Cabral'; José Geilson Alves Demétrio; \\ Maria do Carmo Martins Sobral ${ }^{4}$
}

\begin{abstract}
RESUMO Na técnica de Filtração em Margem (FM) são construídos poços próximos a um manancial superficial, e com a ação do bombeamento cria-se uma diferença de carga hidráulica entre o rio e o aquífero, induzindo a água do rio através do meio poroso até o poço. No caminhamento da água induzida para o subsolo, processos físicos, químicos e biológicos atuam na depuração de contaminantes presentes, sendo obtida uma água bombeada de qualidade superior. A FM é um método de tratamento d’água alternativo eficiente, no qual um dos benefícios imediatos é a capacidade de remoção e/ou redução de diversos contaminantes, a minimização da necessidade do uso de produtos químicos no tratamento convencional e a diminuição de custos. A FM vem sendo usada em diversos países na indústria de abastecimento de água, servindo como o único tratamento necessário ou pelo menos como um pré-tratamento da água superficial contaminada. A remoção de contaminantes depende de diversos condicionantes do meio ambiente ecohidrogeológico. O presente artigo descreve os fundamentos do processo de filtração em margem e apresenta um estudo de caso realizado às margens do rio Beberibe no Estado de Pernambuco. Foram realizados estudos hidrogeológicos, testes para avaliação da condutividade hidráulica, além do monitoramento potenciométrico e de qualidade d'água. Os resultados comprovaram que a água bombeada é uma mistura de água subterrânea e água superficial infiltrada por recarga induzida e confirmaram que a água produzida possui qualidade superior a da água do rio, estando dentro dos padrões de potabilidade.
\end{abstract}

Palavras-Chave - filtração em margem, explotação de água subterrânea, indução de recarga, bacia do rio Beberibe.

ABSTRACT In the Bankfiltration (BF) technique, wells are built near a surface water body, and the pumping action creates a difference in hydraulic head between the river and the aquifer, leading the river water to flow through the porous medium towards the well. On the flow pathway of the induced water through the subsurface, physical, chemical and biological processes work for contaminant removal, and the pumped water presents a higher quality. The BF is an efficient alternative method for water treatment, in which one of the immediate benefits is the ability to remove or reduce several contaminants, minimizing the need for chemical use in conventional treatment and reducing costs. The BF has been used in several countries in the water industry, serving as the only treatment necessary or at least as a pre-treatment of contaminated surface water. The removal of contaminants depends on various conditions of ecohydrogeological environment. This paper describes the fundamentals of the bankfiltration processes and presents a case study carried out on the river Beberibe in Pernambuco State, Brazil. Hydrogeological studies, tests for hydraulic conductivity, potentiometric monitoring and water quality monitoring were performed. Results have showed that the pumped water is a mixture of groundwater and infiltrated surface water by induced recharge and confirmed that the produced water has higher quality than river water, within potability standards.

Keywords: bankfiltration, groundwater production, induced recharge, Rio Beberibe watershed.

\section{INTRODUÇÃO}

A Filtração em Margem (FM), na língua inglesa conhecida como River Bank Filtration (RBF), consiste na utilização de poços próximos a um manancial de superfície de modo que o bombeamento induz uma recarga e obtêm-se água de melhor qualidade. Pode ocorrer naturalmente quando a superfície freática for inferior ao nível d'água superficial do rio (rio influente) ou lago, ou pode ser induzida artificialmente pela locação de poços de bombeamento próximos à água superficial, em outras palavras, recarga casual ou induzida (BOUWER, 2002). Em algumas regiões, as águas do rio percolam naturalmente para o subsolo até os aquíferos (rio influente) durante todo o ano ou em outros casos só durante certo período, quando o rio apresenta condição de elevado nível de água. Durante esse processo de percolação, contaminantes potenciais presentes na água do rio são filtrados e atenuados, devido a processos físico-químicos e biológicos envolvidos, e consequentemente a água fica com uma melhor qualidade, desde que não existam contaminantes nas águas subterrâneas ou se estiverem presentes em baixas concentrações. A FM induzida é utilizada como uma técnica na indústria de abastecimento de água. O principal objetivo desta técnica é um pré-tratamento da água superficial contaminada, previamente aos tratamentos convencionais em estações 
de tratamento de água (ETA) (MASSMANN, 2002).

Filtração em margem é um método de tratamento d'água alternativo eficiente e de baixo custo, no qual um dos benefícios imediatos para o seu uso é a minimização da necessidade do uso de produtos químicos, geralmente utilizados no tratamento convencional das águas superficiais para o controle de patogênicos. Pelo fato desta técnica ser de custo de implantação inferior a uma estação convencional, ou pelo menos reduzir processos mais avançados neste tratamento convencional, a FM é considerada uma técnica que tem uma considerável diminuição de custos.

Esta técnica vem sendo utilizado por diversos países, principalmente na Europa, em zonas de clima temperado, há mais de um século (Gunkel, 2010). O presente artigo descreve os fundamentos do processo de filtração em margem e apresenta um projeto piloto desenvolvido às margens do rio Beberibe no Estado de Pernambuco. O objetivo do projeto piloto foi verificar se o método poderia ser aplicado às condições brasileiras, e principalmente, levando em conta as condições climáticas e hidrogeológicas locais, já que tem sido observado o uso em países de clima temperado e em zonas aluvionares ou bastante arenosas.

\section{FILTRAÇÃO EM MARGEM}

No processo de Filtração em Margem, poços de bombeamento, locados próximo às margens do rio, bombeiam grandes quantidades de água. A ação do bombeamento cria uma diferença de carga hidráulica entre o rio e o aquífero, induzindo a água do rio através do meio poroso até o poço. A água bombeada é uma mistura da água subterrânea originalmente presente no aquífero e da água superficial infiltrada. Dependendo do uso, do grau de filtração e da atenuação do contaminante, a água bombeada já pode ir direto para o sistema de distribuição no abastecimento d'água. Porém, no mínimo serve como um pré-tratamento na produção de água potável (RAY et al., 2002).

A mudança que ocorre na qualidade da água que atravessa o meio poroso tem vários processos envolvidos, os quais podem ser subdivididos em (DOUSSAN et al., 1997): hidrodinâmicos, mecânicos, biológicos, e físico-químicos. Grande parte da purificação da água ocorre pelos processos mecânicos e físico-químicos. Complementarmente, os processos de degradação natural (bioquímicos) ajudam a remoção dos compostos orgânicos dissolvidos, assim como patogênicos, sendo de grande importância para a técnica de recarga artificial como sistema de tratamento.

$\mathrm{O}$ método de FM pode remover eficientemente turbidez, microorganismos, matéria orgânica natural, pesticidas, herbicidas, compostos químicos inorgânicos dissolvidos, fármacos, compostos que causam sabor e odor, pelos processos físicos, químicos e biológicos na passagem através do meio poroso (SAHOO et al., 2005). O processo físico de remoção tende ser mais eficiente quanto menor for a velocidade do fluxo subterrâneo e quando o aquífero for forma- do por material granular bem distribuído, ao mesmo tempo que se observa a importância da camada de interface semipermeável que separa o meio poroso e a água superficial.

Um grande número de variáveis está envolvido para se alcançar melhoria na qualidade da água produzida, podendo ser salientadas algumas: características hidráulicas e composição do material do aquífero; qualidade da água superficial; velocidade de filtração; condutividade hidráulica; distância dos poços ao corpo d'água; vazão de bombeamento; diluição com as águas subterrâneas; temperatura da água superficial; e características dos sedimentos da interface aquífera e água superficial (RAY et al., 2002). A eficiência da remoção de microorganismos depende dos seguintes fatores: da ação dos vários processos de remoção na passagem da água pelo meio poroso; das condições climáticas e hidrológicas; da geometria do poço; das características do material nas margens e do leito do rio / lago; e do fluxo da água subterrânea.

A EPA (Environmental Protection Agency, USA) já considera a filtração em margem como processo de tratamento alternativo do tipo filtração biológica. O processo possibilita a remoção de nutrientes em condições nas quais os microorganismos consomem o carbono orgânico. A FM pode ser usada para remover partículas, bactérias, vírus, parasitas, compostos orgânicos e inorgânicos (EPA, 2007).

Em diversos países o método de FM é reconhecido como um eficiente processo de atenuação natural assegurando sustentabilidade ao abastecimento de água potável (HEBERER et al., 2004). Em Berlin, 100\% do suprimento de água é proveniente de água subterrânea, onde $70 \%$ origina-se da Filtração em Margem e recarga de água subterrânea.

Devido à complexidade dos fatores envolvidos na técnica de Filtração em Margem, é fundamental o conhecimento de múltiplos aspectos, necessitando estudar os vários processos numa multidisciplinaridade e em multiescala. Os projetos de implantação da técnica de Filtração em Margem devem otimizar a necessidade de um volume de água associado com a preservação da qualidade d'água, pelos processos de atenuação e misturas que ocorrem.

\section{PROCESSOS DURANTE A FILTRAÇÃO EM MARGEM}

Para aplicação do método alguns parâmetros devem ser conhecidos, pois influenciam no seu desempenho (HUNT et al., 2002): disponibilidade de água do rio que será induzida para o aquífero; nível de qualidade da água do rio; velocidade do fluxo e característica dos sedimentos do leito do rio; características hidráulicas do meio poroso; sazonalidade do fluxo do rio; e estabilidade do canal do rio. Os fatores que influenciam os processos na Filtração em Margem variam com condições específicas locais. As propriedades dos sedimentos, tais como: distribuição no tamanho dos grãos, permeabilidade e porosidade, assim como o regime de bombeamento, controlam a velocidade de infiltração. Observa-se também que a distribuição sazonal e espacial de matéria orgânica suspensa na superfície da água influencia 
a drenança pela obstrução dos sedimentos no leito do rio.

Com relação à parte construtiva dos poços, há três tipos que têm sido usados no método de filtração em margem: poço coletor horizontal; - poço vertical; e - cacimbão (poço amazonas). Em alguns países são usados os sistemas de galeria de poços verticais, conectados por um tubo sifonado. Existindo apenas uma casa de bombeamento que capta água de todos os poços através da ligação aos tubos sifonados (Figura 1).

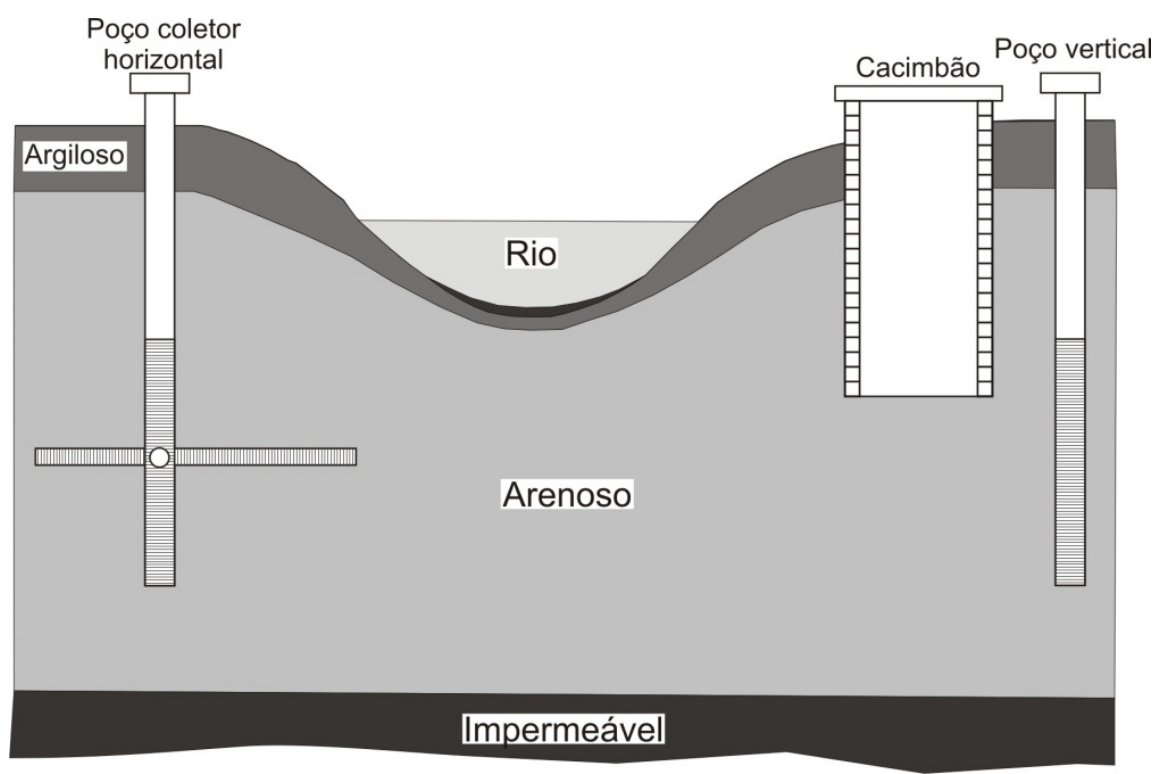

Figura 1. Tipos de poços para o método de Filtração em Margem.

Hiscock e Grischek (2002) relatam que os processos de atenuação na FM acontecem em duas zonas principais: na camada de colmatação ativa biologicamente, onde os processos de degradação intensiva e adsorção ocorrem em curto tempo de residência; e ao longo do caminhamento principal do fluxo entre o rio e o poço de captação, onde as taxas de degradação e capacidade de sorção são menores e o processo de mistura são maiores.

A interface entre água superficial e água subterrânea dentro do aquífero aluvial é reconhecida como um meio ambiente biogeoquímico distinto. Esta zona de transição dinâmica, comumente caracterizada pelos gradientes de luz, temperatura, $\mathrm{pH}$, potencial redox, oxigênio, e carbono orgânico, controla a qualidade da filtração em margem (TUFENKJI et al., 2002). Com a água infiltrada através das margens do rio para o aquífero, ocorrem mudanças químicas descritas por quatro tipos de reações: transferência elétrica; intemperismo; mudança iônica e mudança de gases. Inúmeros estudos apontam como sendo a atividade biológica o principal agente de mudanças químicas, tais como degradação da matéria orgânica ou poluentes orgânicos, e que esta atividade ocorre nos primeiros metros da infiltração.

$\mathrm{O}$ processo $\mathrm{FM}$ tem algumas similaridades quanto ao desempenho da filtração lenta em areia. A matéria orgânica, similar a "película suja", pode criar uma interface aquífero/ rio, especialmente quando a velocidade do fluxo é baixa. Uma cheia no rio poderia limpar esta camada; todavia, com subsequentes períodos de fluxo baixo, pode ser reestabelecida.
Um fator que afeta a velocidade de infiltração na interface de água superficial / água subterrânea é a colmatação, que também pode ocorrer em zonas de recarga artificial. A colmatação pode ser causada por processos químicos, físicos e biológicos. Este efeito pode ser acelerado pela indução da água superficial para o meio poroso. Porém, vale salientar que esse efeito pode estar em constante modificação, dependendo das velocidades de escoamento do rio, ou dos efeitos de cheia. Os processos físicos compreendem a acumulação de sólidos suspensos, orgânicos e inorgânicos. Os processos biológicos referem-se à acumulação de flocos de algas e bactérias na água e na superfície da interface manancial / meio filtrante. Os processos químicos incluem a precipitação de carbonato de cálcio, gipsita, fosfatos e outros compostos químicos sobre o solo e dentro dele (BOUWER, 2002).

Para um projeto de um sistema de FM é necessário uma pré-avaliação das condições locais, e umas das informações relevantes é a condutância da interface água superficial e água subterrânea. Os elementos de controle dos sistemas de FM com relação a sua sustentabilidade são: condutância da interface; transmissividade do aquífero e dinâmica do filtro do poço (HUBBS, 2004).

Para o entendimento da interação complexa que há entre água subterrânea e superficial em relação aos fatores de clima, relevo, geologia, e biota, é necessário uma compreensão estruturada que vem sendo chamado de hidrogeoecológica (SOPHOCLEOUS, 2002). Todos estes aspectos devem ser avaliados num conjunto em 
sua sustentabilidade e suscetibilidade a contaminação, para um gerenciamento efetivo dos recursos hídricos.

A interação de corpos d'água com água subterrânea é governada pela posição da água superficial com relação ao sistema de fluxo de água subterrânea, pelas características geológicas de suas margens, e pelo clima na região. A perspectiva geomorfológica também ajuda a caracterizar esta interação, se há o fluxo do corpo d'água superficial para o subsolo ou o contrário, observando-se as características de declividade da margem, sinuosidade de rio, largura e profundidade do rio, e o sistema de deposição fluvial ou lagunar.

O fluxo estimado do sistema conectado rio / aquífero é uma função da diferença entre o nível do rio e a carga do aquífero, considerado-se que isto é controlado pela drenança através do substrato semipermeável, baseado na lei de Darcy. Simplificadamente, alguns modelos consideram o fluxo variando linearmente com a diferença de carga, porém há equações não-lineares para representar esta interação.

A atividade microbiana diminui a permeabilidade na interface da interação água superficial / água subterrânea devido à formação de um biofilme (TUFENKJI et al., 2002). A redução da permeabilidade pode ocorrer também devido à retenção de partículas finas $(<2 \mathrm{~mm})$ no leito do rio ou devido à obstrução dos sedimentos das margens do rio, ocorrendo principalmente se o rio está sob condições de baixo fluxo. As margens do corpo d'água obstruídas podem aumentar a eficiência da filtração natural, porém a perda na permeabilidade pode reduzir significativamente a produtividade da zona de captação do poço.

\section{QUALIDADE D'ÁGUA}

Para o controle da qualidade da água anterior, nas águas superficiais originalmente, e posterior, na produção de água potável, alguns parâmetros precisam ser analisados e acompanhados durante o processo de tratamento dos contaminantes físicos, químicos e biológicos (RAY et al., 2002). Como parâmetros físicos podem ser citados a temperatura e a turbidez. A temperatura pode variar nas estações de tratamento com fontes de águas superficiais, porém, permanece relativamente constante nas águas subterrâneas. A variação da temperatura pode variar em função do bombeamento, locação do ponto de monitoramento, distância do poço ao rio, construção do poço, ou fatores hidrogeológicos. Variações na temperatura podem influenciar a performance do tratamento d'água, principalmente quando esta modifica substancialmente a viscosidade do fluido. É um parâmetro que deve ser observado, porém no Brasil, mais especificamente nas regiões norte e nordeste, não se tem uma variação de temperatura tão grande nas fontes d'água tanto superficial quanto subterrânea. A turbidez nos cursos d'água, normalmente, é oriunda de trechos onde se atravessa formações ricas em argila. Além do fato de poder ter uma grande variação espacial, verifica-se também uma grande variação sazonal. Por exemplo, dados de monitoramento no rio
Ohio próximo a Louisville, Kentucky/EUA, mostrou uma variação de 2 ntu (julho/99) a 1500 ntu (março/97) durante um período de 5 anos (1997-2002); todavia os poços coletores tiveram turbidez em torno de $0,1 \mathrm{ntu}$. Os parâmetros químicos podem ser divididos em quatro grupos principais: inorgânicos; orgânicos sintéticos; matéria orgânica natural; farmacêuticos e outros químicos emergentes. Os parâmetros biológicos na água superficial incluem protozoários, bactérias e vírus. Giárdia e Cryptosporidium são os protozoários principais. Coliformes totais e fecais são as bactérias monitoradas pelos órgãos ambientais e de vigilância sanitária.

Wang et al. (1995), realizaram estudos em uma estação de tratamento d'água em Louisville, a qual capta do aquífero aluvial que tem interação direta com o rio Ohio (WANG, 2002). Foi analisada a remoção de patogênicos, partículas, turbidez, matéria orgânica natural, subprodutos de desinfecção, e pesticidas. Eles também compararam a FM com os métodos convencionais de tratamento d'água da própria estação. Para indicar a eficiência de remoção é utilizado a expressão x-log, onde crédito de remoção log (na base 10) é uma terminologia usado nos Estados Unidos, o qual refere-se à redução de orgânicos patogênicos. Por exemplo, remoção 1-log é igual a uma redução de $90 \%$ do organismo alvo; 2-log, 99\% de redução; e 3-log, 99,9\% de redução (RAY et al., 2002). Wang et al. (1995) mostraram que FM é eficiente para remoção da matéria orgânica e pesticidas. Remoções de partículas superiores a 2,4 logs foram alcançados com a FM e 1,5 logs de remoção pelos métodos convencionais de tratamento.

\section{ESTUDO DE CASO: RIO BEBERIBE}

Uma pesquisa com Filtração em Margem foi realizada na bacia do rio Beberibe, em Pernambuco. A área estudada está situada na Região Metropolitana do Recife (RMR), na divisa entre Olinda e Recife, limitada pelas coordenadas UTM 9115500 a 9116000 Norte e 289500 a 290000 Leste (Figura 2). A estação elevatória de Caixa d'Água, local da pesquisa, está situada no bairro de Caixa d'Água - Olinda, sendo o rio Beberibe o limite entre os municípios de Olinda e Recife neste trecho da RMR.

A RMR possui economia basicamente urbana, apresentando grandes problemas sociais e relacionados com recursos hídricos e ambientais. Problemas estes que geram contaminação crescente aos corpos hídricos. A RMR possui diversos rios e córregos que cortam seus municípios, dentre estes situa-se o rio Beberibe. O rio Beberibe tem orientação predominante no sentido oeste-leste, mostrando uma deflexão para o sul e desaguando no Oceano Atlântico (PERNAMBUCO - SEPLAN, 1997; PERNAMBUCO - SECTMA, 2006), numa região estuarina compartilhada com o rio Capibaribe.

O rio Beberibe, pela classificação das bacias hidrográficas do estado, faz parte do Grupo de Pequenas Bacias Litorâneas - GL1. A Bacia do Beberibe possui uma área de drenagem de $81 \mathrm{Km}^{2}$, e é formada pelos rios Araçá e Pacas, com nascente no município de Camaragibe (Aldeia). Possui uma 


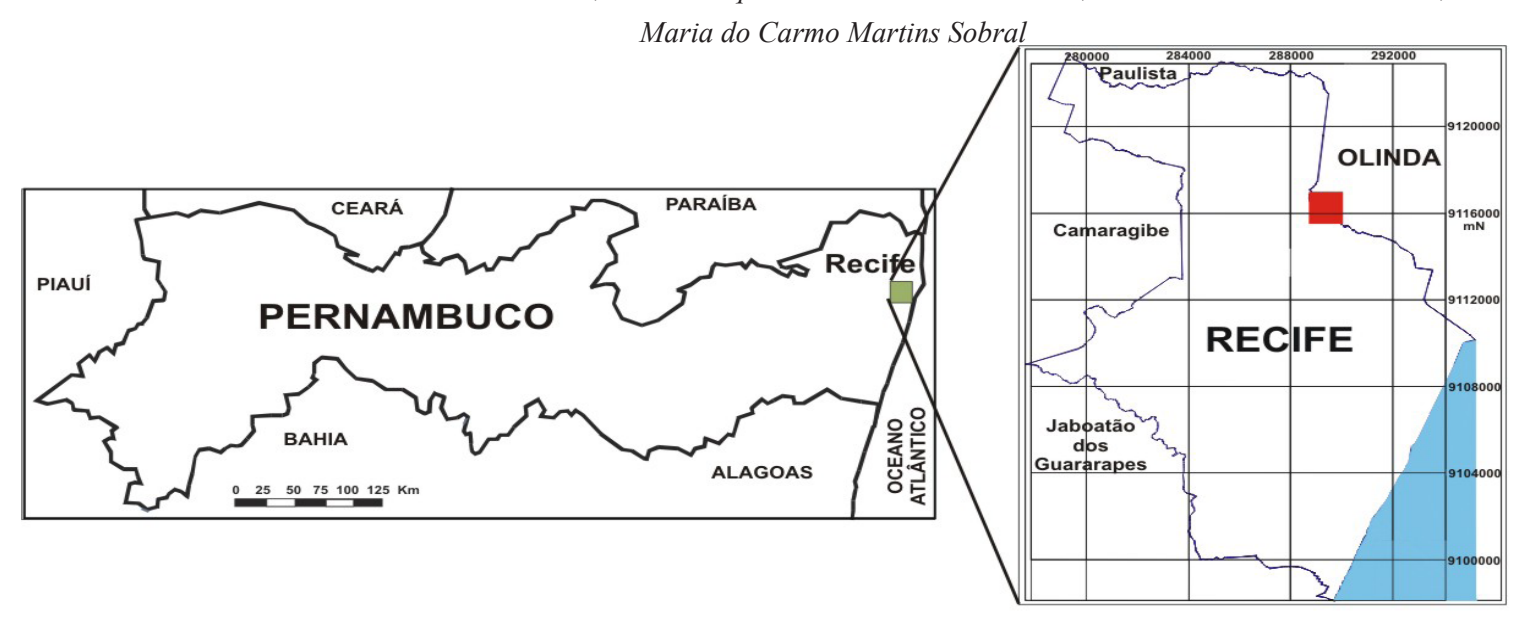

Figura 2. Localização da pesquisa da Filtração em Margem na bacia do rio Beberibe, no limite entre os municípios de Recife e Olinda.

extensão de aproximadamente $19 \mathrm{Km}$, desde a confluência desses dois rios até a desembocadura no Oceano Atlântico. O Beberibe, em períodos normais, é um rio estreito, com largura em torno de 6 metros (PERNAMBUCO - SEPLAN, 1997).

Com relação ao enquadramento dos cursos d'água, após a resolução do CONAMA 357/05, o Estado de Pernambuco revogou os enquadramentos existentes até que seja aprovado novos enquadramentos para os rios em Pernambuco. Segundo o artigo 42 da Resolução CONAMA 357/05 (CONAMA, 2005), enquanto não forem aprovados os respectivos enquadramentos, os rios de água doce ficam enquadrados como classe 2, onde o rio Beberibe se insere. Nessa classe, espera-se que o rio tenha certo padrão de qualidade, no qual, para uso no abastecimento público seria necessário apenas o tratamento convencional.

Segundo dados da rede de monitoramento da Companhia de Meio Ambiente e Recursos Hídricos do Estado de Pernambuco (CPRH), até o trecho que margeia a Estação Elevatória de Caixa d'Água, onde existe um ponto de monitoramento, encontram-se altas taxas de concentração de coliformes fecais. A jusante deste ponto, ocorrem problemas tanto para DBO, OD e coliformes fecais, extrapolando os limites de qualidade da água para a respectiva classe 2 .

As atividades antrópicas impactantes à bacia do rio Beberibe são: atividades industriais, atividades urbanas (esgoto doméstico, escoamento superficial), atividades agrícolas, desmatamento ciliar, construção de rodovias e pontes, escoamento pluvial de rodovias, e lixões.

A bacia hidrográfica do Beberibe situa-se em terrenos sedimentares, representados pelos sedimentos mesocenozóicos do Grupo Paraíba, compostos pelas formações Beberibe, Gramame e Maria Farinha, formando a bacia sedimentar costeira Pernambuco-Paraíba. Identificam-se, também, extensas exposições terciárias constituídas pela Formação Barreiras, bem como quaternárias representadas por terraços marinhos indiferenciados, aluviões e sedimentos de praia, tais como recifes e mangues. A Formação Beberibe é preenchida por arenitos de origem fluvial ou estuarina, estando assentada discordantemente sobre o embasamento cristalino, com uma espessura média de 200 metros, em geral, sem fósseis. Os arenitos e areias quartzosas, silitos e outros sedimentos mais finos armazenam importante reserva de água subterrânea (CAMPOS, 2003). Esta formação Beberibe é composta de uma sequência essencialmente arenosa, com uma espessura média de $200 \mathrm{~m}$, em geral sem fósseis, constituindo-se de arenitos friáveis, cinzentos a cremes, mal selecionados, com componentes argilosos.

A bacia do Beberibe localiza-se na sua maior parte na Formação Barreiras, componente da bacia sedimentar Pernambuco-Paraíba, enquanto que o rio Beberibe corre predominantemente sobre afloramento de rochas sedimentares do aquífero Beberibe e um pequeno trecho a oeste localiza-se sobre rochas do embasamento cristalino. A Bacia Sedimentar Pernambuco-Paraíba é formada pelos sedimentos da Formação Barreiras sobrepostos à Formação Beberibe. A Formação Beberibe aflora em pequenas manchas às margens do rio Beberibe, em Passarinho e Alto do Céu, e entre o rio Morno e o canal do Arruda. Devido ao profundo intemperismo, o reconhecimento de suas camadas em superfície é muito difícil, podendo confundir-se com as camadas da Formação Barreiras (CAMPOS, 2003).

$\mathrm{O}$ aquífero Beberibe pode ser subdividido em duas camadas aquíferas superpostas: uma possui arenitos calcíferos que representam uma fácie litorânea marinha e aparecem apenas em subsuperfície, constituindo-se no Beberibe Superior; enquanto a seção inferior, de caráter arenoso, com algumas intercalações de silte e argila, denomina-se de Beberibe Inferior e apresenta-se como o principal aquífero na RMR. (PERNAMBUCO - SECTMA, 1998).

O local de instalação do projeto ocupa a camada de aluvião às margens do rio Beberibe. A pouca profundidade do poço de produção não chega a atravessar toda a camada 
aluvionar, a qual está afastada do aquífero regional sotoposto por uma camada espessa de argila muito compacta.

\section{MATERIAIS E MÉTODOS}

A área de estudo está localizada em terreno da Compesa (Companhia Pernambucana de Saneamento), onde funciona a Estação Elevatória de Caixa d’Água (Figura 3), situada no trecho médio da bacia do rio Beberibe. Na seleção da área para instalação do projeto piloto, além de uma avaliação prévia de condições hidrogeológicas, por estar situado sobre o aquífero Beberibe Superior, a escolha levou em consideração alguns pontos: a área sendo de propriedade da Compesa, facilitaria a execução dos trabalhos de implantação e operação; o rio Beberibe margeia o terreno da estação elevatória.

Quando a estação elevatória entrou em operação, algumas décadas atrás, havia uma captação a fio d'água do rio Beberibe nas margens da mesma. Mas com o decorrer dos anos a poluição do rio foi se agravando até que esta captação foi desativada, e atualmente a captação a fio d'água no rio Beberibe ocorre em um ponto a alguns quilômetros a montante da estação elevatória. A estação elevatória de Caixa d'Água bombeia água para duas estações de tratamento, de onde segue para distribuição a alguns bairros de Recife e Olinda. A água bruta é oriunda da captação no rio Beberibe, além da produção de alguns poços profundos situados no aquífero Beberibe, ambos à montante da área.

Objetivando um conhecimento mais detalhado das camadas do solo e subsolo na área alvo do estudo, foram realizados 6 furos de sondagem, sendo um deles no leito do rio. O método de execução dos furos de sondagens seguiram as recomendações da ABNT, segundo as normas NBR-8036, NBR-6484, e NBR-6502.

Foram coletadas amostras de solo a cada metro para todos os furos de sondagem realizados, com a finalidade da descrição do material. Em algumas profundidades foram selecionadas amostras, que representassem as distintas mudanças de camadas (Figuras 4 e 5), para serem realizados ensaios de granulometria. Os ensaios foram realizados no Laboratório de Solos da Universidade Federal de Pernambuco - UFPE.

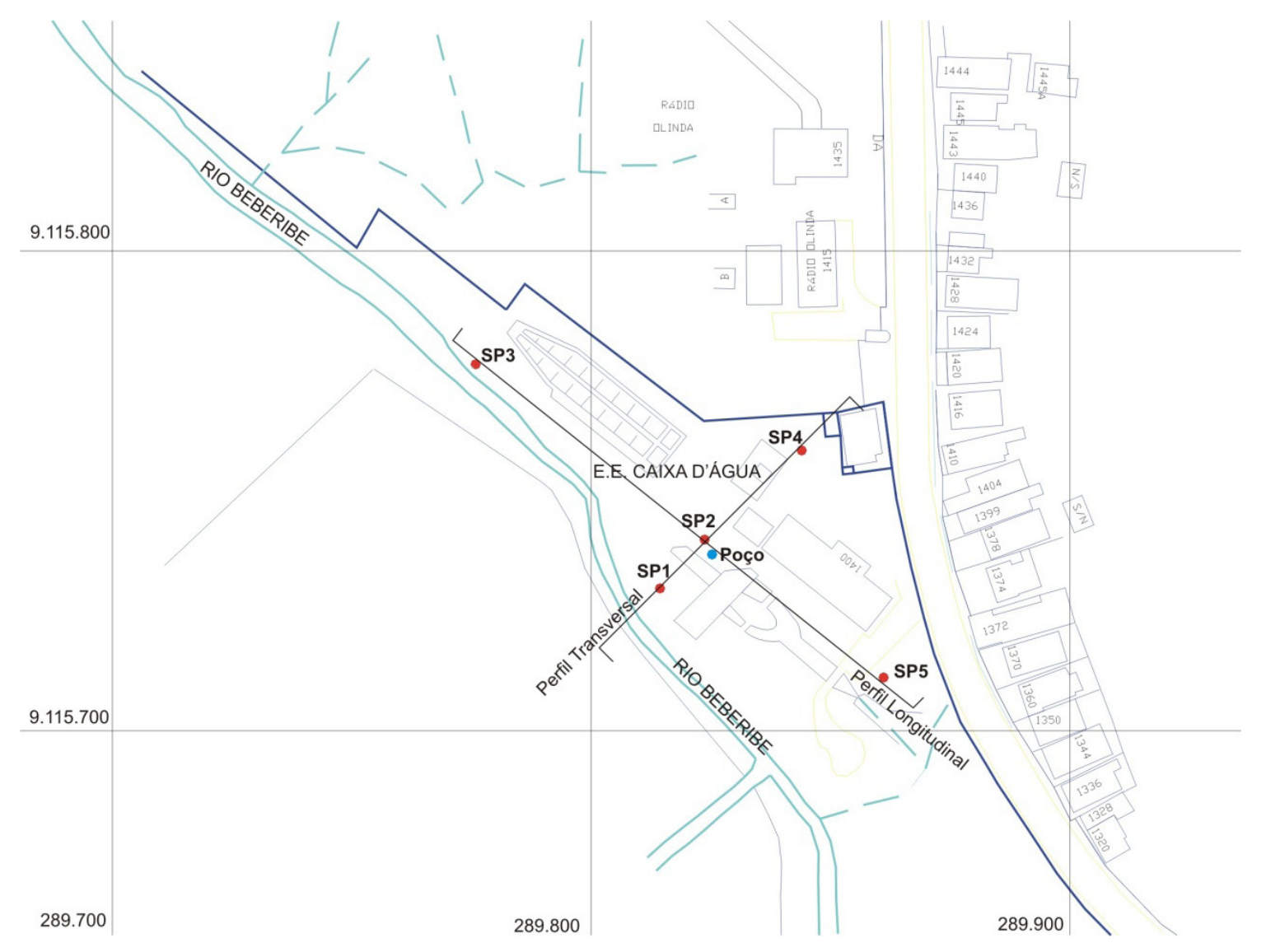

Figura 3. Estação experimental do bairro de Caixa d'Água mostrando o rio Beberibe e a localização das seções transversais.

Conforme definido no planejamento das sondagens, os cinco furos de sondagens foram aproveitados posteriormente para instalação de poços de observação. A construção destes poços de monitoramento foi executada seguindo padrões e recomendações NBR-15495-1/2007 e Norma 6410 da CETESB, tomando atenção para a camada de filtro, colocação do tubo de proteção metálico com tampão, e proteção da parte superficial com base cimentada. Estes poços são constituídos de tubo PVC de 1" (uma polegada) e a extremidade acima do solo foi protegida por um tubo de aço de 1,20 m. A instalação da tubulação para o poço de observação foi feita logo após a conclusão da perfuração de cada um dos furos de 
sondagem, e para o trecho do filtro dos poços foram feitas ranhuras transversais ao tubo a cada $10,00 \mathrm{~cm}, \operatorname{com} 0,80 \mathrm{~mm}$ de espessura, ao longo de 10,00 metros de comprimento, iniciando a partir dos 8,00 metros de profundidade. Também foi utilizado material granular propício para a zona filtrante.

Para a aplicação da técnica de filtração em margem, o poço de produção foi perfurado aproximadamente no centro da área da estação experimental (Figura 3), por ter uma razoável distância às margens do rio e por propiciar uma boa observação pelos poços de observação instalados. O poço de produção possui as seguintes características: profundidade de 15 metros; diâmetro de perfuração 12 1/4 polegadas; método de perfuração rotativa com circulação direta; uma seção de filtro, na profundidade de 6 a 12 metros; diâmetro do poço de 6 polegadas; sendo utilizado tubos de PVC do tipo geomecânico.

Para implantação do projeto piloto com o uso da técnica FM, além das prospecções e ensaios granulométricos, alguns testes foram realizados para averiguação da condutividade hidráulica local. Slug test e bail-down test (EPA, 1994; ASTM, 2002) foram executados em cada um dos 5 poços de observação, sendo obtido uma informação pontual. Foi adotado o Método de Hvorslev como método interpretativo, e os gráficos foram elaborados no software Aquifer Test 3.5.

Com a construção do poço de produção, foi executado o teste de aquífero, que propicia uma informação mais ampla para a área em estudo. Um teste de aquífero foi realizado alguns dias após a execução da perfuração do poço e da limpeza do mesmo. As medições dos rebaixamentos dos níveis nos cinco poços de observação foram realizadas com alguns sensores de nível Levelogger da Solinst e com o uso do medidor de nível tradicional. $O$ teste foi executado a uma vazão constante de $9,5 \mathrm{~m}^{3} / \mathrm{h}$. A vazão foi controlada e observada durante todo o teste através do escoador de orifício circular.

Para uma avaliação do projeto instalado, foi realizado um monitoramento potenciométrico e de qualidade d'água, semanalmente. As leituras dos níveis potenciométricos foram executadas com medidor de nível manual da Brasbailer. No monitoramento de qualidade d'água, amostras foram coletadas do rio Beberibe e do poço de produção. As amostras foram analisadas no Laboratório Agrolab, seguindo as metodologias recomendadas pela APHA - American Public Health Association (APHA, 1998). Os parâmetros monitorados foram: $\mathrm{DBO}_{5,20}$; DQO; amônia; nitrato; nitrito; turbidez; condutividade elétrica; ferro; manganês; cobre; zinco; níquel; cromo; coliformes totais; e Escherichia coli. A seguir são apresentados os resultados e discussões sobre os dados oriundos da pesquisa, e apresentados por Paiva (2009).

\section{RESULTADOS E DISCUSSÃO}

Com as informações obtidas dos perfis de sondagem foram traçadas duas seções litológicas, uma paralela e outra transversal ao rio Beberibe (Figura 3). A seção transversal ao rio Beberibe (Figura 4) inicia-se com material fino, silte-argiloso, gradando imediatamente para uma areia. Em seguida, há presença de um nível argiloso contínuo, argila-siltosa (ao longo de toda a seção), com espessura variando entre 2 e 5 metros. Encontrando-se sob o leito do rio uma camada com turfa. Observa-se, na Figura 4, também contínua em toda a seção, sob a camada argilosa, uma camada com areia grossa, e logo abaixo, uma camada arenosa seguida de uma camada siltosa.A seção paralela ao rio Beberibe (Figura 5) de forma geral confirma o padrão litológico estabelecido na área, evidenciando-se a alternância de material argiloso e arenoso, identificando e individualizando os diferentes níveis, inclusive uma camada de areia grossa e logo abaixo a de areia que são consideradas neste projeto como o horizonte produtor (aquífero).

As figuras 6 e 7 ilustram as curvas granulométricas traçadas para o furo SP5, nas profundidades de 7,00 a 7,45 $\mathrm{m}$ e 15,00 a $15,45 \mathrm{~m}$, respectivamente. A curva para a camada de areia grossa, que pode ser visto nos perfis litológicos (Figura 6), indica grande percentual de areia fina, média e grossa, e também com grande percentual de pedregulho. Já a curva representativa da camada de areia (Figura 7) apresenta grande percentual de areia fina a média. Estas curvas caracterizam a zona de explotação do poço de bombeamento (Figuras 4 e 5).

Os ensaios Slug Test e Bail-Down Test (EPA, 1994; ASTM, 2002) executados nos poços de observação serviram para avaliar o parâmetro de condutividade hidráulica na formação aquífera livre e se há variações espaciais na área da estação elevatória. Os valores observados nos testes não variaram muito de um piezômetro para outro. Como exemplo, os valores fornecidos pelo Aquifer Test para os ensaios Slug Test e Bail-Down Test para o piezômetro SP2 foram 1,7x10-05 $\mathrm{m} / \mathrm{s}$ e $1,4 \times 10^{-05} \mathrm{~m} / \mathrm{s}$, respectivamente. Pode-se considerar que para estes testes em todos os piezômetros ficaram em média em torno de $1,5 \times 10^{-05} \mathrm{~m} / \mathrm{s}$. Os ensaios mostram que na área há uma taxa de condutividade hidráulica razoável, principalmente devido à camada de areia grossa identificada nos perfis litológicos. Como na perfuração dos furos de sondagem utilizou-se bentonita, que talvez tenha penetrado nos poros, é possível que a condutividade hidráulica real seja superior.

O teste de aquífero está sendo representado no gráfico do rebaixamento (Figura 8) com as leituras potenciométricas nos poços SP2 e SP4. Observa-se que ao longo do tempo, ocorre uma mudança de declividade indicando que está chegando água de outro local que não é o aquífero. Esta fonte alcança o horizonte de captação do poço de produção em poucas horas. Isto pode caracterizar que o cone de rebaixamento atingiu uma fonte de recarga, o curso d'água superficial.

Após análise dos resultados do teste, optou-se por instalar no poço de produção um conjunto motor-bomba centrífuga de 1,5 CV. Os rebaixamentos encontrados no poço após a estabilização do sistema em regime permanente é de cerca de 4,7 metros. Após 3 meses com bombeamento ininterrupto, a vazão permanece em torno de $12,5 \mathrm{~m}^{3} / \mathrm{h}$ e o rebaixamento estabilizou no primeiro mês, 


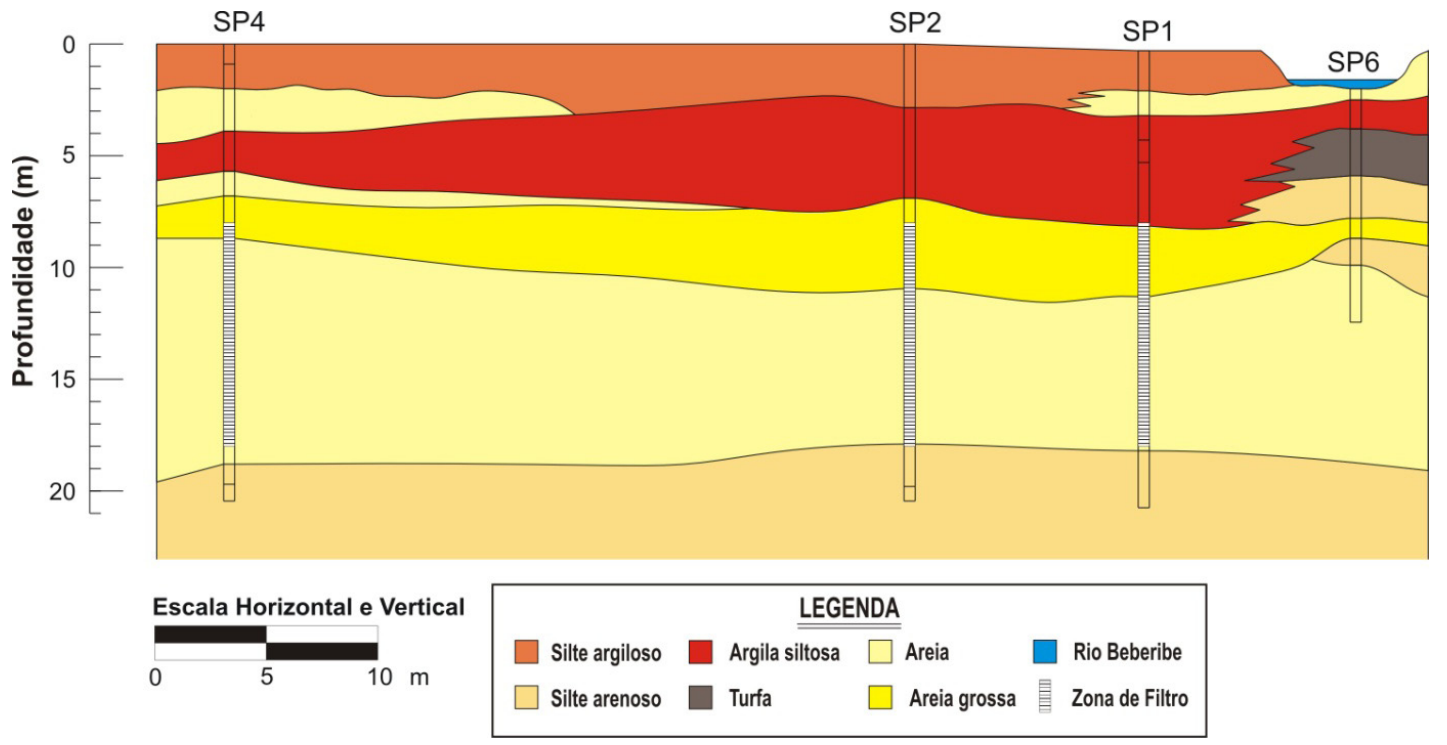

Figura 4. Seção litológica transversal ao rio Beberibe, E.E. Caixa d'Água, Caixa d'Água - Olinda.

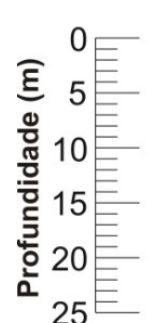

SP5 $\quad$ SP2 SP3

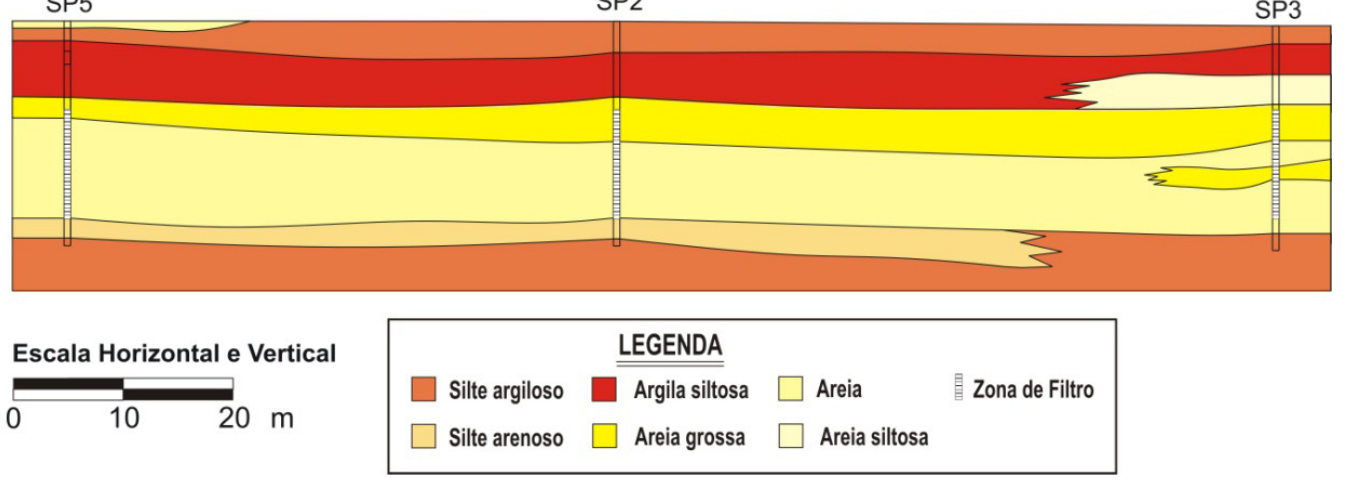

Figura 5.Seção litológica paralela ao rio Beberibe.

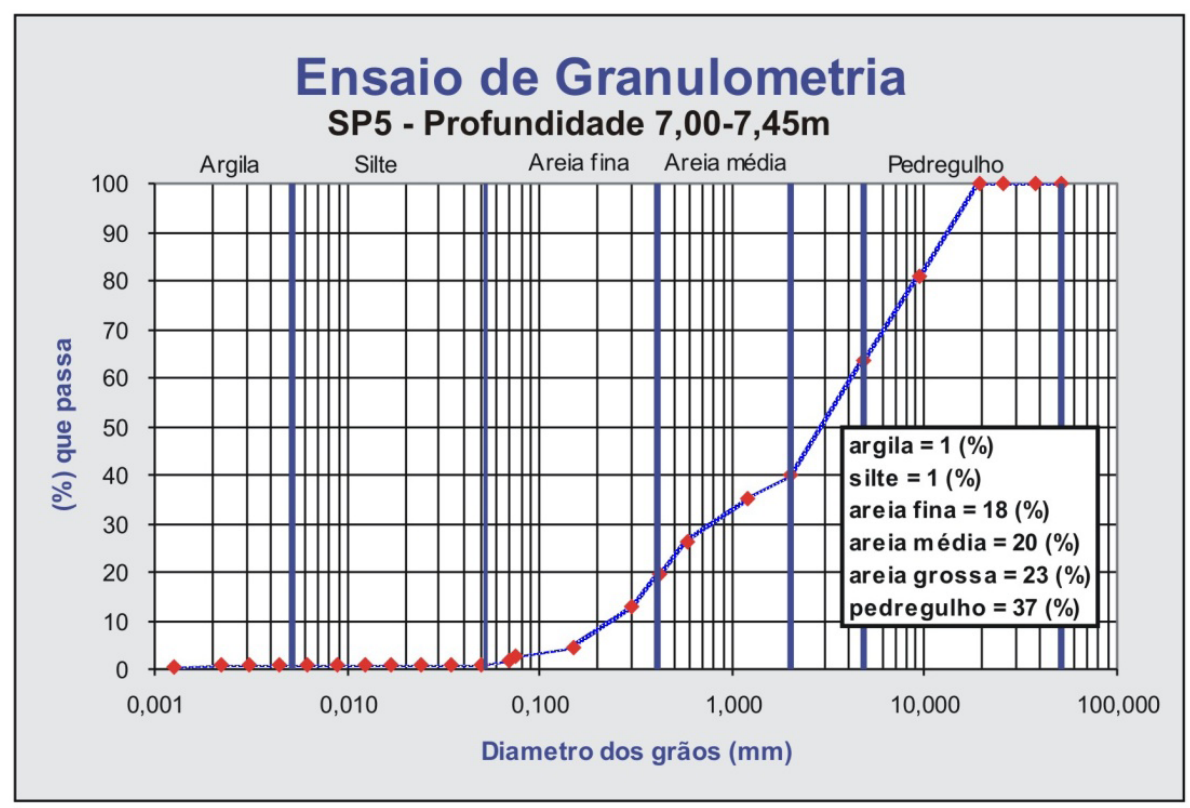

Figura 6. Curva granulométrica para o furo SP5, na profundidade de 7,00 a 7,45 metros. 


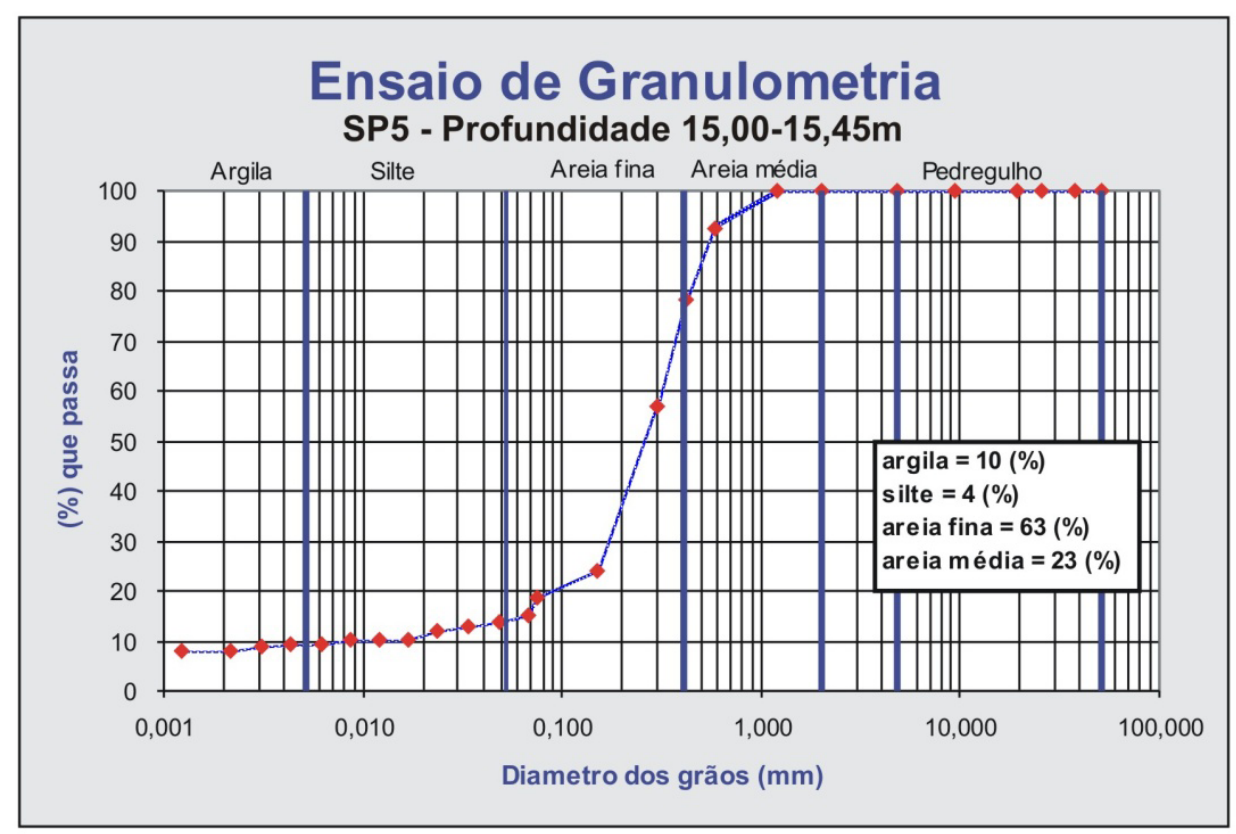

Figura 7. Curva granulométrica para o furo SP5, na profundidade de 15,00 a 15,45 metros.

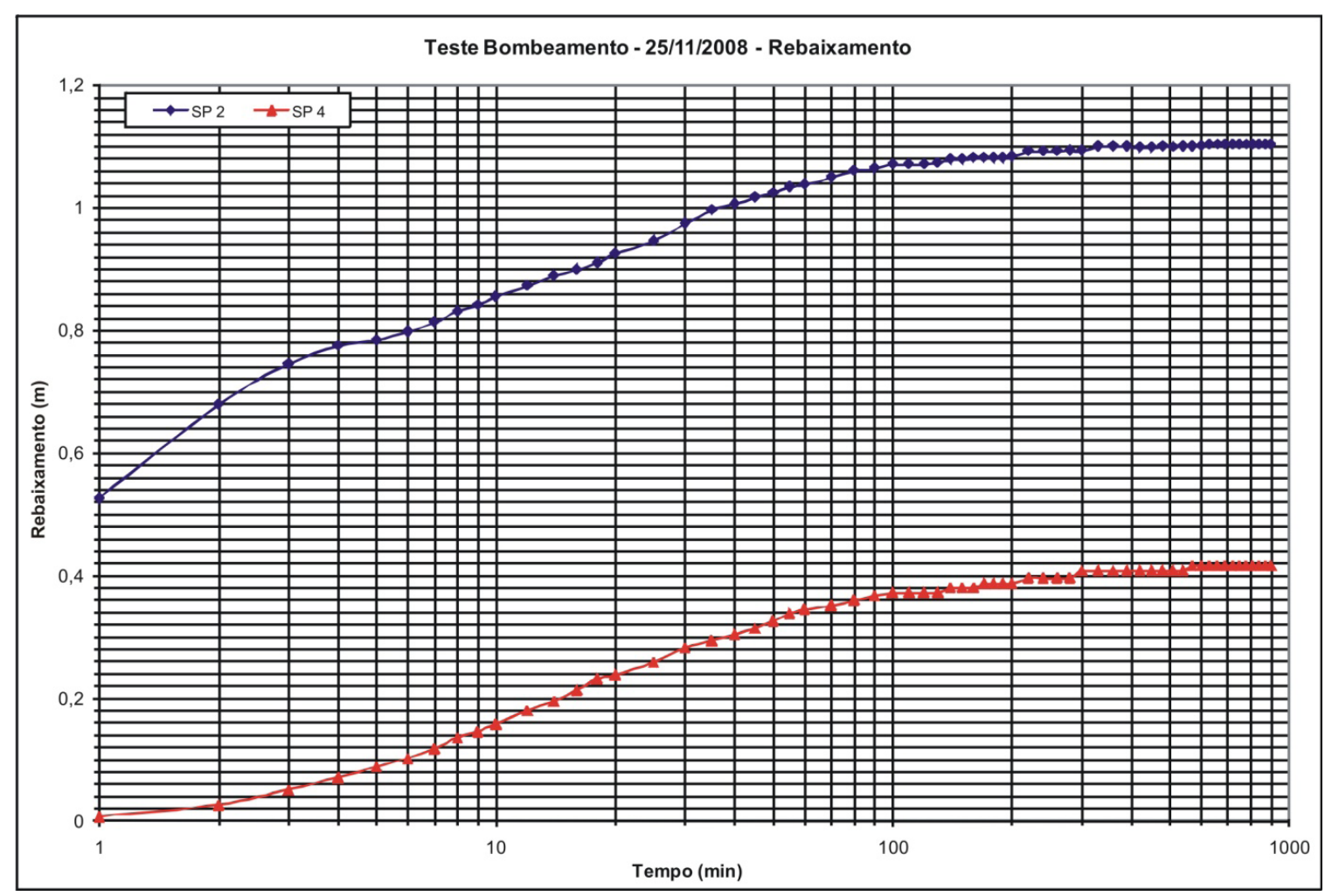

Figura 8. Rebaixamento observado durante o teste de aquífero (eixo do tempo em escala logarítmica).

sendo observado no histórico algumas variações devido aos períodos de chuva, que coincidem com uma elevação no nível do rio e nas leituras dos níveis potenciométricos. Considerando um consumo médio de 200 L/pessoa.dia, o sistema pode abastecer uma comunidade de aproximadamente 1200 pessoas a um custo de tratamento mínimo.

No monitoramento de qualidade d'água, os valores ob-

Águas Subterrâneas, v.24, n.1, p.103-114, 2010 servados para os parâmetros analisados da água do poço de produção estiveram todos dentro dos padrões de potabilidade (MINISTÉRIO DA SAÚDE, 2005), tanto na situação pré e pós bombeamento. Os dados de coliformes totais e Escherichia coli do monitoramento da qualidade mostram que a contaminação não alcançou a região do poço de produção. Com relação à turbidez, obtiveram-se valores praticamente 
zero na água bombeada, devido ao efeito de filtração que ocorre no meio poroso, também demonstrado para os sólidos totais dissolvidos. Os valores de amônia para o rio, indicativo de contaminação fecal ou oriundo da agropecuária, apresentaram-se acima do permitido, segundo a classificação classe 2 do CONAMA (CONAMA, 2005) e portaria 518/04 do Ministério da Saúde. No entanto, esta contaminação não alcançou o horizonte do poço de produção.

Para os metais, os valores observados de ferro, manganês, zinco, níquel, cobre, e cromo apresentaram-se maiores para o rio Beberibe e foram sendo amortizados ao percolar a água pelo meio poroso, de modo que a água extraída do poço apresenta teor de metais abaixo dos limites de potabilidade permitidos pelas normas brasileiras. $\mathrm{O}$ efeito de redução já não ocorre com a salinidade, observado nos valores de condutividade elétrica, pois os sais não são removidos no meio poroso. A tabela 1 mostra a comparação dos valores de alguns dos parâmetros químicos e biológicos observados no monitoramento. A água considerada como sendo representativa para água subterrânea local foi coletada no poço de produção, antes do mesmo entrar em operação. Alguma pequena variação nos valores de qualidade d'água para a água subterrânea pode ser oriunda da perfuração do poço de produção.

Tabela 1. Valores de parâmetros físicos, químicos e biológicos observados no monitoramento, dados do dia 17/03/2009 para amostra de água subterrânea (anterior ao bombeamento) e 03/06/2009 as amostras do rio e poço (FM).

\begin{tabular}{|l|c|c|c|}
\hline Parâmetros & $\begin{array}{c}\text { Água } \\
\text { Subterrânea }\end{array}$ & Rio & Poço (FM) \\
\hline Coliformes Totais $(\mathrm{NMP} / 100 \mathrm{~mL})$ & ND & $>160.000$ & $<2,0$ \\
\hline Escherichia Coli $(\mathrm{NMP} / 100 \mathrm{~mL})$ & $\mathrm{ND}$ & $>160.000$ & $<2,0$ \\
\hline DBO 5,20 (mg/L) & 2,8 & 3,27 & 0,81 \\
\hline DQO $(\mathrm{mg} / \mathrm{L})$ & 10 & 11,00 & 3,00 \\
\hline Amônia $(\mathrm{mg} / \mathrm{L})$ & 0,29 & 0,29 & 0,41 \\
\hline Nitrato $(\mathrm{mg} / \mathrm{L})$ & 0,31 & 0,88 & 0,003 \\
\hline Nitrito $(\mathrm{mg} / \mathrm{L})$ & 0,006 & 5,3 & $\mathrm{ND}$ \\
\hline Ferro $(\mathrm{mg} / \mathrm{L})$ & 0,23 & 1,59 & 0,05 \\
\hline Manganês $(\mathrm{mg} / \mathrm{L})$ & 0,06 & 0,01 & 0,02 \\
\hline Cobre $(\mathrm{mg} / \mathrm{L})$ & $\mathrm{ND}$ & 0,01 & $\mathrm{ND}$ \\
\hline Turbidez $(\mathrm{uT})$ & 1,32 & 14,3 & 0,75 \\
\hline Condutividade Elétrica $(\mathrm{microS} / \mathrm{cm})$ & 158,8 & 219,0 & 226,0 \\
\hline
\end{tabular}

De acordo com as análises dos parâmetros observados na água bombeada, seus valores atenderam os padrões de potabilidade. Poder-se-ia recomendar o uso desta água diretamente para abastecimento, talvez com uma simples cloração. Porém, há necessidade de ampliar as análises com outros parâmetros. No entanto, como o método é novo no Brasil, recomenda-se funcionar como um pré-tratamento das águas do rio Beberibe, que se encontra bastante poluído conforme as observações realizadas tanto no monitoramento da CPRH quanto no monitoramento do projeto piloto.

\section{CONCLUSÕES}

Esse trabalho avaliou uma forma de captação utilizando poços próximos à margem dos rios para obtenção de água com qualidade superior a do rio, de forma a reduzir os custos com tratamento.

$\mathrm{Na}$ tecnologia de Filtração em Margem estão envolvidos vários processos, tais como: adsorção, redução, filtração físico-química, e biodegradação, que em conjunto proporcionam um bom resultado.

Esta pesquisa foi realizada através de um projeto piloto implantado no terreno da estação elevatória de Cai- xa d’Água, em Olinda, na região limítrofe entre Recife e Olinda, com apoio da Compesa (Companhia de Saneamento de Pernambuco) e da Secretaria de Recursos Hídricos de Pernambuco. A Filtração em Margem é uma técnica bem sucedida em muitos países. No nosso país, a técnica está sendo testada em alguns locais, porém não existe ainda uma utilização em escala industrial. No presente projeto foi avaliada a adaptação desta técnica às condições climáticas, fluviais e geológicas na região.

Foi observado que quando o cone de rebaixamento atingiu o rio, o aporte da recarga do rio para o aquífero estabilizou o rebaixamento do lado do rio e continuou praticamente no mesmo nível ao longo de vários meses de bombeamento. Os rebaixamentos observados no poço tem se estabilizado na ordem de 4,7 metros, com algumas variações devido ao período de chuvas. Os rebaixamentos observados mostram uma correlação com o nível do rio.

Os parâmetros físico-químicos observados na água bombeada mostraram-se bem melhores dos que os da água do rio, comprovando o processo de tratamento realizado pelo solo do fundo e pelas margens do curso d'água. No entanto, a condutividade elétrica da água não apresentou redução in- 
dicando que o método não é eficiente para a redução do teor de sais da água infiltrada do rio para o aquífero freático.

Deve-se salientar, que mesmo com a utilização da FM, é necessário um controle eficiente das águas superficiais para evitar impactos maiores com contaminação. A definição de uma área de proteção em torno do poço é essencial para evitar problemas potenciais com a qualidade da água.

A eficiência do método está sendo analisada como um pré-tratamento das águas do rio Beberibe, o qual se encontra bastante poluído, principalmente por esgotos domésticos.

\section{REFERÊNCIAS BIBLIOGRÁFICAS}

AMERICAN SOCIETY FOR TESTING AND MATERIALS - ASTM. (2002). D-4044 1996 (Reapproved 2002) - Standard Test Method (Field Procedure) for Instantaneous Change in Head (Slug) Tests for Determining Hydraulic Properties of Aquifiers. Estados Unidos. APHA - American Public Health Association (1998). Standard Method for the examination of water and wastewater. American Public Health Association, American Water Works Association, Water Environmental Federation, 20 ${ }^{\text {th }}$ Ed. Washington, Estados Unidos.

BOUWER, H., (2002). Artificial recharge of groundwater: hydrogeology and engineering. Hydrogeology Journal, vol.10, p.121-142. CAMPOS , H.L. (2003). Processo Histórico de Gestão na Bacia Hidrográfica do Rio Beberibe (PE): Uma Retrospectiva. Universidade Federal do Rio de Janeiro, Instituto de Geociências. Tese de Doutorado. Rio de Janeiro - RJ. 226p.

CONAMA - Conselho Nacional de Meio Ambiente (2005). Resolução $n^{\circ}$ 357/05 de março de 2005. Dispõe sobre a classificação dos corpos de água e diretrizes ambientais para o seu enquadramento, bem como estabelece as condições e padrões de lançamento de efluentes, e dá outras providências. Disponível em: www. mma.gov.br/port/conama. Acesso em junho de 2009.

DOUSSAN , C.; POITEVIN, G.; LEDOUX, E.; DETAY, M. (1997). River bank filtration: modelling of the changes in water chemistry with emphasis on nitrogen species. J. Contam. Hydrol. 25, 129-156.

ENVIRONMENTAL PROTECTION AGENCY - EPA (1994). 2046 - Slug Tests. Estados Unidos. p.1-5.

ENVIRONMENTAL PROTECTION AGENCY - EPA (2007). Office of Ground Water and Drinking Water Effect of Treatment on Nutrient Availability. Total Coliform Rule Issue Paper. 45p.

GUNKEL, G. (2010). Bank filtration - an eco-technology for drinking water treatment and the application to the semi-arid zone. Second International Conference: Climate, Sustainability and Development in Semi-arid Regions. 16a 20 de Agosto de 2010. Fortaleza, Ceará, Brazil

HEBERER, T.; Mechlinski, A.; Fanck, B.; Knappe, A.; Massmann, G.; Pekdeger, A.; e Fritz, B. (2004).
Alcançando os resultados esperados, abre-se a perspectiva da utilização do método em outros locais do estado de Pernambuco. Atualmente, a Compesa vem se utilizando da água captada pelo poço de produção. Apesar de ser uma pequena parcela de contribuição para o volume de água distribuído, o uso da técnica mostrou-se promissor e com possibilidades de ampliação. As pesquisas nesta área experimental seguirão a linha investigativa de como está ocorrendo a interação entre a água superficial e subterrânea, e quantificar a taxa de contribuição de volume d'água através do rio.

Field Studies on the Fate and Transport of Pharmaceutical Residues in Bank Filtration. Ground Water Monitoring \& Remediation. Vol.24, n.2. HISCOCK, K.M., Grischek, T. (2002). Attenuation of groundwater pollution by bank filtration. Journal of Hydrology. Vol.266, p.139-144.

HUBBS, S.A.(2004).Processesinvolvedin mechanicalclogging of riverbank filtration systems. NATO Advanced Research Workshop, Samorin, Slovakia. September 7-10, 2004. <http://www.soulstatic.com/NATORBF/papers/hubbs/ hubbs.pdf $>$ (acessado em março de 2007).

HUNT, H.; Schubert, J.; e Ray, C. (2002). Riverbank Filtration - Improving Source-Water Quality. Chapter: Conceptual Design of Riverbank Filtration Systems. Kluwer Academic Publishers. California, USA.

MASSMANN, G. (2002). Infiltration of River Water into the Groundwater: Investigation and Modeling of $\mathrm{Hy}$ draulic and Geochemical Processes during Bank Filtration in the Oderbruch, Germany. Universidade Livre de Berlim, Tese de Doutorado. Berlim, Alemanha.

MINISTÉRIO DA SAÚdE (2005). Portaria $\boldsymbol{M S} \boldsymbol{n}^{\circ} \mathbf{5 1 8}$, de 25 de março de 2004. Estabelece os procedimentos e responsabilidades relativos ao controle e vigilância da qualidade da água para consumo humano e seu padrão de potabilidade, e dá outras providências. Brasília, DF: Ministério da Saúde.

PAIVA, A. L. R. (2009). O processo de Filtração em Margem e um Estudo de Caso no rio Beberibe. Universidade Federal de Pernambuco, Doutorado em Engenharia Civil - Área de Tecnologia Ambiental e Recursos Hídricos. Tese de Doutorado. Recife - PE. 149 p. PERNAMBUCO - GOVERNO DO ESTADO DE PERNAMBUCO. SECTMA - Secretaria de Ciência, Tecnologia e Meio Ambiente (1998). Plano Estadual de Recursos Hídricos - PERH. Recife - PE. PERNAMBUCO - GOVERNO DO ESTADO DE PERNAMBUCO. SECTMA - Secretaria de Ciência, Tecnologia e Meio Ambiente (2006). Atlas de Bacias Hidrográficas de Pernambuco. Coordenação Técnica de Simone Rosa da Silva. 104p. Recife - PE. PERNAMBUCO - GOVERNO DO ESTADO DE PERNAMBUCO. SEPLAN - Secretaria de Planeja- 
mento (1997). Projeto de Qualidade das Águas e Controle da Poluição Hídrica das Bacias dos Rios Beberibe, Capibaribe e Jaboatão - PQA $\boldsymbol{P E}$. Estudos de Consolidação e Compementação do Diagnóstico sobre a Qualidade das Águas, Relativos à Preparação do Programa de Investimentos nas Bacias dos Rios Beberibe, Capibaribe e Jaboatão. Relatório n.1, Tomos I e II. Recife - PE.

RAY, C.; SCHUBERT, J; LINSKY, R.B; MELIN, G. (2002). Riverbank Filtration - Improving Source-Water Quality. Chapter: Introduction. Kluwer Academic Publishers. California, USA. SAHOO, G.B.; RAY, C.; WANG, J.Z.; HUBBS, S.A.; SONG, R.; JASPERSE, J.; SEYMOUR, D. (2005). Use of artificial neural networks to evaluate the effectiveness of riverbank filtration. Water Research, v.39, p. 2505-2516. SOPHOCLEOUS, M. (2002). Interactions between groundwater and surface water: the state of the science. Hydrogeologic Journal. Vol.10, p.52-67.
TUFENKJI, N.; Ryan, J. N.; E Elimelech, M. (2002). Bank filtration: a simple technology may inexpensively clean up poor-quality raw surface water. Environmental Science \& Technology. Colorado, USA. p. 423 - 428. WANG, J.; J. SMITH; and L. DOOLEY (1995). Evaluation of riverbank infiltration as a process for removing particles and DBP precursors. Proceedings, Water Quality Technology Conference, American Water Works Association, Denver, Colorado. WANG, J. (2002). Riverbank Filtration - Improving Source-Water Quality. Chapter: Riverbank Filtrate Case Study at Louisville, Kentucky. Kluwer Academic Publishers. California, USA.

\section{AGRADECIMENTOS}

Os autores agradecem à COMPESA, à SRH-PE e ao CNPq pelo apoio nas diversas fases do projeto. $\mathrm{O}$ primeiro autor agradece ao $\mathrm{CNPq} / \mathrm{CT}$-Hidro pela atual bolsa de doutorado, e a CAPES/DAAD pelo estágio de doutorado realizado na Freie Universität Berlin. 